ARTIGOS

\section{DISCLOSURE DE RESPONSABILIDADE SOCIAL EM EMPRESAS DO SETOR DE BIOCOMBUSTÍVEL DA BM\&F BOVESPA}

\section{RESUMO}

Por muito tempo, tem-se discutido a importância da evidenciação de informações sobre a Responsabilidade Social das empresas, tornando os efeitos de suas atividades econômicas mais transparentes para a sociedade. $\mathrm{O}$ interesse nessas informações não é exclusividade do governo, mas também dos stakeholders, (proprietários, gestores, trabalhadores e investidores potenciais). O objetivo deste trabalho é calcular e avaliar as informações referentes ao disclosure voluntário e involuntário de responsabilidade social disponibilizadas em websites das empresas produtoras de petróleo, gás e biocombustíveis vinculadas ao novo mercado do BM\&F Bovespa. Esta pesquisa possui uma abordagem qualitativa com amostra não probabilística, intencional e por conveniência. Os resultados apontam que, de maneira geral, o disclosure voluntário é mais evidenciado que o disclosure obrigatório. A Empresa Petrobras foi a que apresentou maiores níveis de divulgação obrigatória e voluntária. Em relação aos itens de análise, observou-se que "comportamento ético" (60\% de disclosure) e "Respeito pelas normas internacionais de comportamento" (66\% de disclosure), ambos pertencentes à divulgação voluntária, apresentaram os níveis mais altos de divulgação.

Palavras-chave: Responsabilidade Social. Disclosure. Biocombustível.

\section{INTRODUÇÃO}

Por muito tempo, tem-se discutido a importância em evidenciar as demonstrações contábeis de forma transparente, seguindo não só as normas internacionais de contabilidade (IFRS), como também a legislação vigente no Brasil. O interesse na correta evidenciação dessas informações não é exclusividade do governo, mas também dos proprietários, gestores, trabalhadores e investidores potenciais.

Segundo Bueno (1999), para as companhias que emitem valores mobiliários (ações ou debêntures), é importante que as demonstrações sejam devidamente evidenciadas, passando confiança e transparência aos usuários das informações contábil/financei- 
ra. Quatro categorias contribuem na prática do disclosure:

a) o ambiente em que a empresa está inserida;

b) o mercado de capitais;

c) as influências não financeiras e;

d) a resposta corporativa às demandas por maior transparência (CHOI; MUELLER, 1992).

No que se refere aos estudos de contabilidade ambiental, observa-se que, no Brasil, estes estudos têm focado no disclosure dos passivos ambientais e nas externalidades ecológicas, embora já existam pesquisas sobre o disclosure ambiental de empresas brasileiras (MUSSOI; BELLEN, 2010). Para Conceição et al. (2011), os estudos sobre evidenciação de responsabilidade social se iniciaram na década de 1960, nos Estados Unidos e na França, utilizando a estatística para mensuração das relações de emprego, mobilidade social e utilização do lucro.

Segundo Souza (1995), várias entidades nacionais e internacionais têm buscado melhores práticas de disclosure, tais como o American Institute of Certified Public Accountants (AICP), o International Accounting Standards Board (IASB), o Financial Accounting Standards Board (FASB), o Conselho Federal de Contabilidade (CFC), o Instituto dos Auditores Independentes do Brasil (IBRACON) e a Comissão de Valores Mobiliários (CVM). Especificamente no Brasil, a ISO 26000 tem fundamentado e evidenciado a Responsabilidade Social e, segundo Conceição et al. (2011), esta norma possui não somente o propósito de incorporar as questões socioambientais nos processos decisórios empresariais, mas também, e principalmente, de se responsabilizar pelos impactos das decisões tomadas.

Conforme Cordeiro (2003), entende-se que evidenciação, disclosure ou revelação é toda informação divulgada pela empresa que venha a auxiliar os analistas financeiros de forma mais precisa, revelando a situação econômica, financeira e social da empresa de forma totalmente transparente. Disclosure é a divulgação deliberada de informações das empresas ao mercado, sejam elas quantitativas ou qualitativas, obrigatórias ou voluntárias, com meios formais ou informais (BUENO, 1999).

A evidenciação de Responsabilidade Social tem o intuito de satisfazer a demanda da sociedade em obter informações em contrapartida aos lucros obtidos pelas empresas, ou seja, é uma forma de realizar uma prestação de contas das empresas com a sociedade. Diante da contextualização acima, a problemática de pesquisa consiste em descobrir qual o grau de disclosure (voluntário e obrigatório) de responsabilidade social das empresas do setor de petróleo, gás e biocombustíveis? Visando responder a essa problemática, o presente trabalho tem como objetivo calcular e avaliar as informações referentes ao disclosure voluntário e involuntário de responsabilidade social disponibilizadas em websites das empresas produtoras de petróleo, gás e biocombustíveis vinculadas ao novo mercado do BM\&F Bovespa. A justificativa é que, apesar de ser um tema de fundamental importância em um momento em que as políticas públicas não atendem efetivamente às necessidades da população e as empresas possuem maior poder devido à globalização e à concentração de mercado, não se pode afirmar que a responsabilidade social corporativa e o disclosure voluntário e involuntário sejam uma prática efetiva das organizações.

\section{RESPONSABILIDADE SOCIAL CORPORATIVA (RSC)}

As organizações vêm empreendendo ações sociais, por meio de uma postura considerada socialmente responsável, que vão desde a tradicional filantropia até as parcerias com o terceiro setor. Entre essas ações, incluem-se programas de voluntariado empresarial e de proteção ao meio ambiente, além da instituição de códigos de ética que visam a regulamentar a conduta de seus membros internamente e com a sociedade (SOARES, 2004). Carroll (1999) apontava para a evolução dos conceitos de RSC e as aplicações das empresas no âmbito dos negócios, e atualmente a responsabilidade social 
corporativa pode ser entendida como uma dupla resposta à atual crise vivenciada pelo capital. A primeira delas, nos termos da dominação da empresa na sociedade atual. A segunda, no sentido de que a mudança nos padrões da concorrência decorrente da crise econômica obriga as organizações a adaptarem seu processo de trabalho às novas exigências do mercado globalizado e a adequarem sua estrutura aos padrões de parceiros internacionais ou aos requisitos desdobrados por meio de processos de fusão e incorporação (SOARES, 2004).

Segundo Carroll e Shabana (2010), o conceito de responsabilidade social tem crescido em termos de importância e significância para as organizações, colocando em conflito a ideia de maximização de lucro como o objetivo maior de um negócio, tal como afirmava Friedman (1962). Neste sentido de importância e significância para a organização, Garriga e Melé (2004) abordam quatro grupos gerais de teorias para a RSC: Teorias Instrumentais; Teorias Políticas; Teorias de Integração e Teorias Éticas.

Entretanto, outros grupos de teorias visam a integrar negócios com demandas sociais dependendo da sociedade para sua existência, continuidade e crescimento. Um exemplo é o gerenciamento dos stakeholders, abordagem desenvolvida para gerenciar todas as partes interessadas que são afetadas pelas políticas corporativas e práticas. Esta abordagem, originada nos anos 70 (por exemplo, por Sturdivant (1979)), visa a integrar os grupos com interesse na companhia dentro do processo de tomada de decisão. $\mathrm{O}$ grupo de teorias éticas foca nos requerimentos éticos que embasam o relacionamento entre negócios e sociedade.

Claro, Claro e Amancio (2008) abordam que o desenvolvimento sustentável destaca a visão de longo prazo como um dos princípios básicos de sustentabilidade, uma vez que os interesses das futuras gerações devem ser analisados. Esses princípios da sustentabilidade devem nortear as remodelações dos valores da sociedade e o próprio paradigma do mundo dos negócios, de forma a incorporar práticas sustentáveis em suas ações. Nesta perspectiva, existe atualmente um movimento globalizado agindo no intuito de modificar políticas públicas, processos produtivos e estilo de vida da sociedade em busca do desenvolvimento sustentável.

Conforme Murcia e Santos (2010), o discurso explicitado prega que a adoção de programas de responsabilidade social corporativa implica atitudes éticas em relação ao meio ambiente, ao trabalhador e aos demais stakeholders da empresa. Podem-se, contudo, assinalar diversas contradições entre o que é assumido como uma postura ética e o que é efetivamente praticado no mundo organizacional, no qual predomina, ainda que muito queiram negar, o interesse do capital sobre todos os outros. Por outro lado, Garriga e Melé (2004) concluem que as mais atuais teorias de Responsabilidade Social Corporativa focam nos seguintes aspectos: atender objetivos que produzam lucros de longo prazo; usar força do negócio de forma responsável; integrar demandas sociais e contribuir para uma boa sociedade fazendo o que é eticamente correto.

Neste contexto, empresas vêm demonstrando cada vez mais suas práticas sociais por meio de relatórios de RSC (como balanço social). Assim, muitas empresas já fizeram muito para melhorar as consequências dos impactos social e ambiental de suas atividades. Todavia, este esforço ainda não é tão produtivo quando deveria, por duas razões:

a) os negócios são colocados em posições divergentes com a sociedade, quando os dois lados são totalmente interdependentes;

b) há uma pressão sobre as empresas por pensar na responsabilidade social de uma forma genérica, e não na forma que seja mais apropriada para sua estratégia; Normalmente as práticas de RSC são desconectadas do negócio e de sua estratégia (POTTER; KRAMER, 2006).

Os autores entendem que é necessário pesar investimentos em RSC x valor agregado para a empresa, pois de nada adianta investimentos pesados em RSC se eles não agregarão 
o suficiente na vantagem competitiva da organização. Para os autores, a empresa deve assumir uma postura que:

a) não tente substituir as obrigações do governo;

b) seja seletiva nos investimentos em RSC de forma que não só gerem benefícios à sociedade, mas também agreguem vantagem competitiva para a empresa.

Assim, pode-se argumentar que é necessário alinhar práticas de RSC à estratégia e sua vantagem competitiva.

\section{DISCLOSURE OBRIGATÓRIO}

Em um mercado globalizado e altamente competitivo, é de suma importância que as empresas disponibilizem a seus usuários não somente as informações obrigatórias exigidas por lei, mas, também, evidenciem outras informações que venham a influenciar a tomada de decisão de seus usuários Oliveira, Benetti e Varela (2011). O Conselho Federal de Contabilidade - CFC criou a Resolução 1.003/2004 que aprova a NBC T15, que trata da evidenciação das informações de natureza social e ambiental. No mesmo caminho, a Comissão de Valores Mobiliários - CVM aprova um novo pronunciamento com a deliberação 594/2009, que trata da evidenciação de informações contábeis. Este pronunciamento passou a ter seus efeitos nas demonstrações contábeis encerradas em dezembro de 2010, as quais devem ser divulgadas juntamente com as de 2009 para fins de comparação (IUDÍCIBUS et al., 2010).

O disclosure está entre os temas de destaque nas pesquisas sobre a teoria da contabilidade e, por consequência, na prática contábil. $\mathrm{O}$ disclosure, ao reduzir a incerteza da informação fornecida pelas organizações, corrobora, significativamente, a eficiência do mercado de capitais, no que tange à gestão de riscos, e também a melhor compreensão da informação contábil por seus diversos usuários (OLIVEIRA; BENETTI; VARELA, 2011).

Segundo Lima (2007), o disclosure de uma organização não pode ser somente um con- junto de informações determinadas por lei, mas por todas as informações que contribuam para a tomada de decisão dos stakeholders. No Brasil, o disclosure é obrigatório por lei, devendo as companhias de capital aberto divulgarem, periodicamente, as informações exigidas pela Comissão de Valores Mobiliários. Conforme Dantas et al. (2004), o que deve ser observado é a quantidade de informação evidenciada pela empresa; é o equilíbrio entre o custo/benefício da divulgação, no qual os benefícios decorrentes dessa informação têm que exceder o custo de produzi-la, sempre observando se há claras evidências sobre os benefícios que um maior nível de disclosure trará para a empresa como, também, para os usuários e tomadores de decisão.

No Brasil, de forma geral, a evidenciação de informações no mercado de valores mobiliários, especialmente as demonstradas em notas explicativas, não tem observado grande importância. O disclosure, em sua maioria, tem-se limitado ao que é compulsório, e assim se observa que a presença do órgão regulamentador é de suma importância, visando garantir a informação tempestiva, relevante e útil para evitar o uso de práticas que possam colocar em desconfiança o mercado mobiliário (CVM, 2015). Segundo Farias (2004), a evidenciação das informações contábeis deve estar presente no relatório da administração e nas demonstrações contábeis, embora deva receber a complementação de notas explicativas e o parecer dos auditores independentes. Diante do cenário econômico atual, os investidores cada vez mais se utilizam da evidenciação contábil, caracterizando, assim, sua fundamental importância para corrigir as imperfeições do mercado (GODOY; COSTA, 2007).

\section{DISCLOSURE VOLUNTÁRIO}

Souza (1995) entende que disclosure é a divulgação da informação contábil para o mercado, seja ela quantitativa ou qualitativa; obrigatória ou voluntária. Essas informações servem para a organização externalizar aos seus stakeholders o que está sendo feito para a 
melhoria e manutenção do bem-estar da sociedade e do meio ambiente (LINDBLOM, 1994).

Leuz e Verrecchia (2000) destacam que as empresas podem, voluntariamente, adotar padrões internacionais de contabilidade para a comunicação internacional em vez de suas normas internas. Os autores ainda ressaltam que as Normas Internacionais de Relato normalmente exigem aumento dos níveis de divulgação, o que é susceptível de ser avaliado pelos investidores.

Toms (2002), Hasseldine, Salama e Toms (2005) afirmam que o disclosure de informações socioambientais é o sinal que as empresas emitem para aumentar a reputação dos stakeholders. Os autores ainda sugerem que o disclosure socioambiental está relacionado à reputação na medida em que empresas com boa reputação corporativa são estimuladas a apresentar boas práticas socioambientais a seus stakeholders.

Fernandes (2011) destaca a existência de duas modalidades de disclosure socioambiental, são elas:

a) obrigatório, quando exigido por leis e regulamentos (VERRECCHIA, 1983) e;

b) voluntário, quando feito espontaneamente, mesmo que seja com base em diretrizes e orientações.

Cardoso, De Luca e Gallon (2014, p. 27) expõem que, ao selecionar as informações a serem divulgadas, "identificam-se disposições que não possuem caráter obrigatório, demonstrando-se a necessidade do questionamento sobre a identificação dos aspectos influenciadores da prática do disclosure voluntário e como estes se comportam". Os autores destacam ainda que a disponibilidade pode ocorrer por meio de relatórios corporativos que podem englobar tanto informações obrigatórias quanto informações voluntárias, quantitativas ou qualitativas, positivas ou não.

Bushman e Smith (2001) afirmam que a divulgação de informações relevantes minimiza a assimetria de informação no mercado e, consequentemente, reduz o risco de decisões equivocadas por parte dos usuários, em todas as esferas. Nesse sentido, para melhor compreender o disclosure socioambiental, faz-se necessário atender às particularidades da responsabilidade social, bem como identificar o perfil dos usuários desse tipo de informação e suas demandas. Oliveira (2005) expõe que não existe uma definição consensual sobre o que seja responsabilidade socioambiental.

Segundo Farias (2004), as empresas devem evidenciar a seus usuários não somente as informações compulsórias, mas todas as que possam contribuir de forma positiva para a tomada de decisão. O disclosure não pode restringir-se ao que determina a lei; informações complementares podem e devem ser evidenciadas, visando à transparência das demonstrações contábeis; o disclosure voluntário é composto por todas as informações não obrigatórias por lei, mas contribui com a transparência da empresa e suas demonstrações contábeis (LIMA, 2007).

\section{METODOLOGIA}

Esta pesquisa é do tipo descritiva com análise qualitativa, pois pretende-se ver a relação do objeto de estudo com a realidade. A amostra é não probabilística, intencional e por conveniência. O setor escolhido é o Petróleo, gás e biocombustível, e o segmento é o "Exploração e/ou Refino" composto por seis empresas, conforme descrição no quadro 1 :

\begin{tabular}{|l|l|}
\hline \multicolumn{1}{|c|}{ Descrição das empresas } & \multicolumn{1}{c|}{ Código } \\
\hline OGX PETRÓLEO E GÁS S.A & NOVA OLEO \\
\hline ÓLEO E GÁS PARTICIPAÇÕES S.A & OGX PETRÓLEO \\
\hline PETRO RIO S.A & PETRORIO \\
\hline PETRÓLEO BRASILEIRO S.A PETROBRAS & PETROBRAS \\
\hline QGEP PARTICIPAÇÕES S.A & QGEP PART \\
\hline REFINARIA DE PETROLEOS MANGUINHOS S.A. & PET MANGUINH \\
\hline
\end{tabular}

Quadro 1- Relação das empresas da pesquisa

Fonte: BM\&FBOVESPA 
Vale ressaltar que este setor foi escolhido para esta pesquisa devido à importância para a economia brasileira no que se refere à capacidade de produção de bens e serviços, principalmente originado de recursos energéticos de origem fóssil. Contudo, esta fonte de energia vem passando por evoluções progressivas devido à crescente importância do uso de energia renováveis (CONFEDERAÇÃO NACIONAL DA INDÚSTRIA, 2012). Dessa forma, a interação entre os setores de energia baseados nos derivados de petróleo e na bioenergia aporta ao país vantagens competitivas à sociedade.

As informações foram retiradas exclusivamente da internet no mês de julho de 2015 , por meio da website de cada empresa, bem como da Bolsa de Valores brasileira. O instrumento de pesquisa (Check List) foi construído de acordo com a Norma Brasileira de contabilidade Técnica 15 (NBC T15) para o disclosure obrigatório, e para o disclosure voluntário, foram utilizadas as normas da ISO 26000. O Check List foi dividido em duas categorias: disclosure obrigatório, composto pelos seguintes grupos de análise: 1 - Geração e distribuição de riqueza, 2 - Recursos humanos, 3 - Interação da entidade com o ambiente externo, 4 - Interação com o meio ambiente e 5 - Informações referente à auditoria externa; e disclosure voluntário, composto pelos grupos: 6 -Accountability, 7 - Transparência, 8 - Comportamento ético, 9 - Respeito pelos interesses das partes interessadas, 10 - Respeito pelo estado de direito, 11 - Respeito pelas normas internacio- nais de comportamento e 12 - Respeito pelos direitos humanos.

O índice disclosure foi construído com a atribuição de uma nota 1 (um) para cada quesito informado pela empresa e nota 0 (zero) para o caso contrário. Dessa forma, após a identificação dos quesitos de cada empresa, foram somados os pontos de cada um e divididos pelo total de quesitos, o que resulta em 75 questões, sendo 54 na categoria de disclosure obrigatório e 21 na categoria disclosure voluntário.

O tratamento dos dados se deu, inicialmente, por meio da construção do índice de divulgação (disclosure) de cada empresa e, em seguida, a análise individual e outra análise comparativa das empresas do setor.

\section{ANÁLISE DOS RESULTADOS}

O objetivo desta pesquisa é calcular e avaliar as informações referentes ao disclosure voluntário e involuntário de responsabilidade social disponibilizadas em websites das empresas produtoras de petróleo, gás e biocombustíveis vinculadas ao novo mercado do BM\&F Bovespa. Dessa forma, a primeira análise refere-se ao disclosure obrigatório e, em seguida, ao disclosure voluntário. A tabela 1 mostra os resultados obtidos sobre a evidenciação das empresas pesquisadas, referentes a cada questão, e agrupados nos grupos de 1 a 5 que se referem ao disclosure obrigatório, e nos grupos de 6 a 12, que integram o disclosure voluntário.

Tabela 1-Check-List do disclosure obrigatório e voluntário

\begin{tabular}{lccc}
\hline QUESTÕES & TOTAL & QE & Percentual (\%) \\
\hline DISCLOSURE OBRIGATÓRIO & & & \\
$\mathbf{1}$ - Geração e distribuição de riqueza & & & \\
1.1 - A riqueza gerada e distribuída pela entidade está apresentada na & 6 & 6 & 100,00 \\
DVA? & &
\end{tabular}

\section{2 - Recursos Humanos}

\section{1 - Remuneração e benefícios}

2.1.1- Consta a remuneração e os benefícios concedidos aos 6
empregados?

$\begin{array}{lllll}\text { 2.1.2 - A empresa evidencia a composição do corpo funcional? } & 6 & 5 & 83,33\end{array}$

2.1.3 - A empresa evidencia as contingências?

$6 \quad 4 \quad 66,67$

2.1.4 - A empresa evidencia os passivos trabalhistas?

$\begin{array}{lll}6 & 4 & 66,67\end{array}$


2.1.5 - A empresa evidencia a remuneração bruta segregada por empregados, administradores, terceirizados e autônomos?

2.1.6 - A empresa evidencia a maior e a menor remuneração da entidade, considerando os empregados e os administradores?

2.1.7 - A empresa evidencia os gastos com encargos sociais?

2.1.8 - A empresa evidencia os gastos com alimentação?

2.1.9 - A empresa evidencia os gastos com transporte?

2.1.10 - A empresa evidencia os gastos com previdência privada?

2.1.11 - A empresa evidencia os gastos com saúde?

2.1.12 - A empresa evidencia os gastos com segurança e medicina do trabalho?

2.1.13 - A empresa evidencia os gastos com educação? (excluindo os de educação ambiental)

2.1.14 - A empresa evidencia os gastos com cultura?

2.1.15 - A empresa evidencia os gastos com capacitação e desenvolvimento profissional?

2.1.16 - A empresa evidencia os gastos com creches ou auxílio-creches?

2.1.17 - A empresa evidencia as participações nos lucros ou resultados?

2.1.18 - Os itens acima estão divulgados por quantidades de empregados autônomos, terceirizados e administradores?

\section{2 - Composição dos Recursos Humanos}

2.2.1 - A empresa evidencia o total de empregados no final do exercício?

2.2.2 - A empresa evidencia o total de admissões?

2.2.3 - A empresa evidencia o total de demissões?

2.2.4 - A empresa evidencia o total de estagiários no final do exercício?

2.2.5 - A empresa evidencia o total de empregados portadores de necessidades especiais no final do exercício?

2.2.6 - A empresa evidencia o total de prestadores de serviços terceirizados no final do exercício?

2.2.7 - A empresa evidencia o total de empregados por sexo?

2.2.8 - A empresa evidencia o total de empregados por faixa etária?

2.2.9 - A empresa evidencia o total de empregados por nível de escolaridade?

2.2.10 - a empresa evidencia o total de ocupantes de cargos de chefia por sexo?

2.3 - Informações sobre ações trabalhistas

2.3.1 - A empresa evidencia o número de processos trabalhistas movidos contra a entidade?

2.3.2 - A empresa evidencia o número de processos trabalhistas julgados procedentes?

2.3.3 - A empresa evidencia o número de processos trabalhistas julgados improcedentes?

2.3.4 - A empresa evidencia o valor total de indenizações e multas pagas por determinação da justiça?

\section{3 - Interação da entidade com o ambiente externo}

3.1 Informações referente a investimento na comunidade

3.1.1 - A empresa evidencia investimentos com educação? (exceto a de caráter ambiental)

3.1.2 - A empresa evidencia investimentos com cultura?

3.1.3 - A empresa evidencia investimento com saúde e saneamento?

$\begin{array}{lll}6 & 2 & 33,33 \\ 6 & 1 & 16,67 \\ 6 & 1 & 16,67\end{array}$


3.1.4 - A empresa evidencia investimentos com esporte/lazer? (exceto os patrocínios com finalidade publicitária)

3.1.5 - A empresa evidencia investimentos com alimentação?

6

3.2 Informações sobre investimentos com interação em clientes

3.2.1 - A empresa evidencia o número de reclamações recebidas diretamente na entidade?

3.2.2 - A empresa evidencia o número de reclamações recebidas por meio de órgãos de proteção e defesa do consumidor?

3.2.3 - A empresa evidencia o número de reclamações recebidas por meio da justiça?

3.2.4 - A empresa evidencia o número de reclamações atendidas em cada instância arrolada?

3.2.5 - A empresa evidencia o montante de multas e indenizações a clientes, determinadas por órgãos de proteção e defesa do consumidor ou pela justiça?

3.2.6 - A empresa evidencia as ações empreendidas pela entidade para sanar ou minimizar as causas das reclamações?

3.3 Informações sobre fornecedores

3.3.1 - A empresa evidencia critérios de responsabilidade social para a seleção de seus fornecedores?

\section{4 - Interação com o meio ambiente}

4.1 - A empresa evidencia investimentos e gastos com manutenção nos processos operacionais para a melhoria do meio ambiente?

4.2 - A empresa evidencia investimentos e gastos com a preservação e/ ou recuperação de ambientes degradados?

4.3 - A empresa evidencia investimentos e gastos com a educação ambiental para empregados, terceirizados, autônomos e administradores da entidade?

4.4 - A empresa evidencia investimentos e gastos com educação ambiental para a comunidade?

4.5 - A empresa evidencia investimentos e gastos com outros projetos ambientais?

4.6 - A empresa evidencia quantidade de processos ambientais, administrativos e judiciais movidos contra a entidade?

4.7 - A empresa evidencia valor das multas e das indenizações relativas à matéria ambiental, determinadas administrativa e/ou judicialmente?

4.8 - A empresa evidencia passivos e contingências ambientais?

\section{5 - Informações referente a auditoria externa}

5.1 - A empresa divulga o relatório sobre informações ambientais revisadas pela auditoria externa?

\section{DISCLOSURE VOLUNTÁRIO}

\section{6 - Accountability}

6.1 - A empresa apresenta algum relatório que evidencia os impactos de sua atividade na sociedade?

6.2 - A empresa apresenta algum relatório sobre as tomadas de decisão para evitar repetição de impactos negativos não intencionais ou imprevistos?

\section{7 - Transparência}

7.1 - A empresa evidencia o propósito, natureza e localização de suas atividades?

\begin{tabular}{|c|c|c|}
\hline 6 & 1 & 16,67 \\
\hline 6 & 1 & 16,67 \\
\hline 6 & 1 & 16,67 \\
\hline 6 & 1 & 16,67 \\
\hline 6 & 1 & 16,67 \\
\hline 6 & 0 & - \\
\hline 6 & 0 & - \\
\hline 6 & 0 & - \\
\hline 6 & 1 & 16,67 \\
\hline 6 & 2 & 33,33 \\
\hline 6 & 1 & 16,67 \\
\hline 6 & 0 & - \\
\hline 6 & 0 & - \\
\hline 6 & 1 & 16,67 \\
\hline 6 & 0 & - \\
\hline 6 & 1 & 16,67 \\
\hline 6 & 2 & 33,33 \\
\hline 6 & 1 & 16,67 \\
\hline
\end{tabular}


7.2 - A empresa evidencia qualquer controle acionário na atividade da organização?

6

6

100,00

7.3 - A empresa evidencia como as decisões são tomadas, são implementadas e analisadas, incluindo a definição de papéis, responsabilidades, accountabilities e autoridades nas diferentes funções dentro da organização?

7.4 - A empresa evidencia padrões e critérios usados para avaliar seu próprio desempenho em relação à responsabilidade social?

7.5 - A empresa evidencia seu desempenho em questões relevantes e significativos da responsabilidade social?

7.6 - A empresa evidencia as origens, montantes e aplicações de seus recursos financeiros referente a responsabilidade social?

\section{8 - Comportamento ético}

8.1 - A empresa identifica e declara seus valores e princípios fundamentais?

8.2 - A empresa desenvolve e usa estruturas de governança que ajuda a promover o comportamento ético dentro da organização, em seu processo decisório e em suas interações com outros?

8.3 - A empresa evidencia a prevenção ou solução de conflitos de interesse em toda a organização que poderia levar a um comportamento antiético?

8.4 - A empresa evidencia a criação e manutenção de mecanismos de supervisão e controle para monitorar, apoiar e exigir comportamento ético?

8.5 - A empresa evidencia o respeito ao bem-estar dos animais, quando suas vidas e existência forem afetadas?

\section{9 - Respeito pelos interesses das partes interessadas}

9.1 - A empresa evidencia a identificação das partes interessadas?

9.2 - A empresa evidencia o reconhecimento de que as partes interessadas podem afetar significativamente as atividades da organização?

9.3 - A empresa evidencia a consideração do ponto de vista das partes interessadas, cujos interesses possam ser afetados por uma decisão ou atividade, mesmo que não tenham um papel formal na governança da organização ou não estejam conscientes desses interesses?

\section{0 - Respeito pelo estado de direito}

10.1 - A empresa evidencia o cumprimento de requisitos legais em todas as jurisdições em que opera, mesmo que essas leis e regulamento não sejam fiscalizados adequadamente?

10.2 - A empresa evidencia a avaliação periódica em conformidades com a lei e regulamentos aplicáveis?

\section{1 - Respeito pelas normas internacionais de comportamento}

11.1 - A empresa evidencia o respeito às normas internacionais de comportamento?

\section{2 - Respeito pelos direitos humanos}

12.1 - A empresa evidencia o respeito pelos direitos humanos?

$6 \quad 4 \quad 66,67$

$6 \quad 2 \quad 33,33$

12.2 - A empresa evidencia o respeito à universalidade desses direitos?

Fonte: adaptado pelos autores deste trabalho com base em Conselho Federal de Contabilidade (2004) e Associação Brasileira de Normas Técnicas (2010). 
O grupo 1 "Geração e Distribuição de Riqueza" interroga se a riqueza gerada consta na Demonstração do Valor Adicionado (DVA). Os resultados evidenciam que todas as seis empresas pesquisadas mostraram em seus relatórios a riqueza gerada, conforme é demandado pela norma NBC T15. Este resultado corrobora os achados de Conceição et al. (2011), e de certa forma, já era esperado, por este indicador ser umas das referências básicas de investidores externos na bolsa de valores brasileira para avaliar as condições financeiras e econômicas das empresas.

O item sobre remunerações e benefícios, do grupo 2 "Recursos Humanos", evidencia se a remuneração bruta era segregada por empregados, administradores, terceirizados e autônomos. Os dados mostram que nenhumas das empresas pesquisadas evidenciam esta informação em seus relatórios, bem como a questão sobre os gastos com transporte. Quatro das seis empresas pesquisadas evidenciam os passivos trabalhistas, bem como as contingências, e este indicador é importante para o investidor por mostrar a relação da empresa com seus empregados. Entretanto, no que se refere à evidenciação de gastos com encargos sociais, alimentação, previdência privada, saúde, segurança e medicina do trabalho, bem como a educação, cultura, capacitação de funcionários, auxíliocreche e participação nos lucros, apenas a Petrobras divulgou esses itens em seus websites no relatório anual de sustentabilidade. No item "composição dos recursos humanos", composto por dez questões, somente uma empresa (Petrobras) divulgou o quesito que se refere à evidenciação do total de empregados portadores de necessidades especiais. Entretanto, no item "Informações sobre ações trabalhistas", nenhuma empresa evidenciou tais informações.

O grupo 3 "interação da entidade com o ambiente externo", ilustrado na tabela 1, é subdividido em outros três itens $(3.1,3.2$ e 3.3). O item 3.1 "informações referentes ao investimento na comunidade" contém 5 questões e foi constatado que duas empresas (Petrobras e QGEP) evidenciam investimentos em educação na comunidade. É válido ressaltar, no en- tanto, que neste item não consta investimento em educação ambiental. As outras questões dizem respeito a investimentos em cultura, saúde, saneamento, esporte, lazer e alimentação na comunidade, e somente a empresa Petrobras evidenciou tais investimentos. Quanto ao item 3.2 "Informações sobre investimentos com interação em clientes", a Petrobras foi a única que divulgou o número de reclamações recebidas na entidade, sendo também a única a tornar público o número de reclamações recebidas por meio de órgãos de proteção e defesa do consumidor e reclamações recebidas por meio judicial. Entretanto nenhuma das empresas pesquisadas evidenciou o montante de multas e indenizações a clientes ou as ações empreendidas para sanar as causas de tais reclamações. O item 3.3 traz questões sobre "Informações sobre fornecedores", e a Petrobras foi a única empresa que evidenciou critérios de responsabilidade social para seleção de fornecedores.

O grupo 4 "interação com o meio ambiente" foi composto por 8 questões que demonstram que as empresas Petrobras e QGEP evidenciam os investimentos e gastos na manutenção dos processos operacionais para melhoria do meio ambiente. Entretanto, somente a Petrobras evidencia investimentos e gastos com preservação e/ou recuperação de ambientes degradados. Outro importante quesito que compõe este grupo, refere-se à evidenciação de investimentos e gastos com educação ambiental para empregados, terceirizados, autônomos e administradores da entidade e comunidade; neste quesito, observa-se que nenhuma empresa evidencia dados em seus relatórios disponibilizados em seus websites. Nesta mesma linha, nenhuma das empresas evidenciou a quantidade de processos ambientais, administrativos e judiciais. Somente a Petrobras evidencia os valores de multas e indenizações relativas à questão ambiental.

O grupo 5 "Informações referente a auditoria externa" é composto por uma única questão, e o seu resultado foi que somente a Petrobras divulgou relatório sobre as informações ambientais revisadas por uma auditoria. 
O grupo 6 "Accountability", possui duas questões e os resultados mostram que a Petrobras evidencia os impactos de suas atividades na sociedade. No que se refere à evidenciação sobre as tomadas de decisões para prevenir ou evitar repetições de impactos negativos imprevistos, somente, as empresas Petrobras e QGEP mostram tais dados em seus relatórios.

O grupo 7 "Transparência" é composto por sete questões que se referem à evidenciação sobre o propósito, natureza e localização das atividades das empresas, bem como a evidenciação sobre qualquer controle acionário na atividade da organização. Os resultados mostram que todas as empresas pesquisadas evidenciam tais relatórios, entretanto em relação à evidenciação sobre como as decisões são tomadas nas empresas, somente a Petrobras e a QGEP evidenciam tais relatórios. Os quesitos referentes à evidenciação sobre padrões e critérios próprios para avaliar o desempenho em relação à responsabilidade social e o desempenho relevantes sobre responsabilidade social foram evidenciados somente a Petrobras mostra tais relatórios. Contudo, a origens dos recursos para o financiamento da responsabilidade social, nenhuma empresa evidenciou.

Ainda retratado na tabela 1 , o grupo 8 "Comportamento Ético" foi o que obteve maior nível de evidenciação pelas empresas. Este item é composto por 5 quesitos e o que apresentou menor percentual de disclosure se refere à evidenciação do respeito ao bem-estar dos animais: somente a Petrobras e a QGEP apresentaram relatórios sobre esta atividade. Quanto à apresentação dos valores e princípios da empresa, bem como o desenvolvimento de uma estrutura de governança que ajude a promover o comportamento ético, solução de conflitos de interesse da organização e mecanismos de supervisão e controle do comportamento ético, quatro das seis empresas evidenciaram estes dados: Nova Oleo, AGX Petroleo, Petrobras e QGEP.

Por meio da análise das respostas do grupo 9 "Respeito pelos interesses das partes interessadas", observa-se que a Petrobras evidencia a identificação das partes interessadas e reconhece que as estas podem influenciar sua atividade. Neste último comentário, a QGEP reconhece a influência das partes interessadas em sua atividade.

O grupo 10 "Respeito pelo estado de direito" contém duas questões que evidenciam que as empresas Nova Oleo, AGX Petroleo, Petrobras e QGEP cumprem os requisitos legais de todas as jurisdições em que operam, mesmo que elas não sejam fiscalizadas a contento. Em relação à avaliação periódica das conformidades da lei e regulamento, somente a empresa Petrobras e a Nova Oleo evidenciam tais procedimentos.

Sobre o grupo 11 "Respeito pelas normas internacionais de comportamento", composto por uma única questão, as empresas Nova Oleo, AGX Petroleo, Petrobras e QGEP evidenciam o respeito por tais normas.

O grupo 12 "Respeito pelos direitos humanos" é composto por dois quesitos, e os resultados indicam que as empresas Nova Oleo, Petrobras e QGEP evidenciam o respeito pelos direitos humanos. Entretanto, somente a Petrobras e a QGEP evidenciam o respeito à universidade desses direitos.

A Tabela 2 foi criada com o intuito de verificar o nível de disclosure por grupo. Os três grupos que apresentaram maior nível de disclosure foram os grupos 1 "Geração e distribuição de riqueza" (100\%); 11 "Respeito pelas normas internacionais de comportamento" (66,67\%); e 8 "Comportamento ético" $(60 \%)$ 
Tabela 2 - Média de percentuais de disclosure, por grupo

\begin{tabular}{lc}
\hline \multicolumn{1}{c}{ GRUPO } & Percentual (\%) \\
\hline 1 - Geração e distribuição de riqueza (DO) & 100,00 \\
11 - Respeito pelas normas internacionais de comportamento (DV) & 66,67 \\
8 - Comportamento ético (DV) & 60,00 \\
10 - Respeito pelo estado de direito (DV) & 50,00 \\
7 - Transparência (DV) & 44,44 \\
12 - Respeito pelos direitos humanos (DV) & 41,67 \\
9 - Respeito pelos interesses das partes interessadas (DV) & 27,78 \\
- Accountability (DV) & 25,00 \\
- Recursos Humanos (DO) & 23,15 \\
5 - Informações referente a auditoria externa (DO) & 16,67 \\
3 - Interação da entidade com o ambiente externo (DO) & 15,00 \\
4 - Interação com o meio ambiente (DO) & 14,58 \\
\hline
\end{tabular}

DV - Disclosure Voluntário; DO - Disclosure Obrigatório

Fonte: dados da pesquisa (2015).

Ainda conforme a tabela 2, metade das empresas evidenciam informações sobre o grupo 10 "Respeito pelo estado de direito", e em relação aos outros oito grupos de análise, observou-se uma baixa adesão das empresas em evidenciar tais informações.

Os grupos que apresentaram menores índices de evidenciação foram o grupo 4 (14,58\%), grupo $3(15 \%)$ e o grupo $5(16,67 \%)$, relacionados ao meio ambiente, ambiente externo e auditoria externa, respectivamente. Dessa forma, há indícios de que o setor não está dando a devida importância ao ambiente externo.

O grupo 2 (Recursos Humanos) apresentou índice de $23,15 \%$ e mostra que a pesquisa identificou que o setor evidencia devidamente as informações básicas, tais como remuneração e corpo funcional; contudo, pouco se divulga sobre os benefícios para os empregados, terceirizados e autônomos, bem como sobre gastos com a cultura e a educação para empregados e ainda o setor não evidenciou sobre as informações das ações trabalhistas.

Ainda na mesma tabela, o grupo 6 ( $a c$ countability) obteve índice de $25 \%$ o que denota pouca importância do setor para com este indicador, pois há indícios de que o setor não se importa com o impacto de suas atividades na sociedade. Outro grupo que obteve um baixo percentual em relação à sua importância é o grupo 12 "Respeito pelos direitos humanos"
$(41,67 \%)$, ou seja, mais da metade do setor não evidenciou os quesitos para identificar o respeito aos direitos humanos e isso mostra que, enquanto a sociedade não cobrar dessas empresas este componente, o mesmo será negligenciado por tais empresas.

Tabela 3 - Índice Disclosure

\begin{tabular}{cc}
\hline & Disclosure \\
\hline PETROBRAS & $80 \%$ \\
QGEP PART & $39 \%$ \\
NOVA OLEO & $24 \%$ \\
AGX PETROLEO & $17 \%$ \\
PET MANGUINH & $13 \%$ \\
\hline PETRORIO & $8 \%$ \\
\hline Média do setor & $30 \%$ \\
\hline
\end{tabular}

Fonte: dados da pesquisa (2015).

A Tabela 3 mostra o índice disclosure por empresa do setor pesquisado e a empresa Petrobras obteve o melhor índice de evidenciação de suas informações $(80 \%)$ e demonstra que a referida empresa possui uma preocupação em revelar as informações para a comunidade interna e externa. Apesar da alta evidenciação da Petrobras, o nível de disclosure do setor estudado foi de $30 \%$, provocado pelas demais empresas, que obtiveram índices de divulgação inferior a $40 \%$. Dessa forma, percebe-se um es- 
forço focalizado em evidenciar as informações ambientais, que ainda não é partilhado dentro do setor. Faz-se necessário que o setor amplie sua divulgação de informações, por se tratar de um relevante segmento para a economia mundial, cuja atividade afeta diretamente o meio ambiente.

Tabela 4 - Índice disclosure segregado

\begin{tabular}{lcc}
\hline \multicolumn{1}{c}{ EMPRESAS } & \multicolumn{2}{c}{ Disclosure } \\
& Obrigatório & Voluntário \\
\hline PETROBRAS & $74 \%$ & $95 \%$ \\
QGEP PART & $26 \%$ & $71 \%$ \\
NOVA OLEO & $15 \%$ & $48 \%$ \\
PET MANGUINH & $15 \%$ & $10 \%$ \\
AGX PETROLEO & $9 \%$ & $38 \%$ \\
PETRORIO & $7 \%$ & $10 \%$ \\
\hline
\end{tabular}

Fonte: dados da pesquisa (2015).

A Tabela 4 mostra a composição do índice disclosure segregado entre as informações obrigatórias e as informações voluntárias. À exceção da PET MANGUINH, o disclosure obrigatório foi menor que o disclosure voluntário nas empresas pesquisadas. As empresas AGX e Petrorio obtiveram os piores níveis de divulgação obrigatória, ou seja, dos 54 itens, apenas divulgaram $9 \%$ e $7 \%$ respectivamente. Com relação ao disclosure voluntário, a empresa Petrobras evidenciou 95\% dos 21 itens disponíveis, apresentando um alto nível de divulgação de informações que não são cobradas por nenhum órgão regulador.

Esta divulgação espontânea de informações se coaduna com a ideia de Dantas et al. (2014), que afirmam que as empresas precisam transcender o objetivo econômico e entender que as mesmas possuem responsabilidades para com a sociedade. A maior transparência em relação às evidenciações voluntárias pode indicar uma tentativa de melhorar a reputação das organizações no mercado, atraindo novos investimentos; sugerindo também que as empresas não devem somente atender às responsabilidades exigidas por lei, e sim evidenciar a prestação de contas com a sociedade de suas atividades para que assim haja um desenvolvimento social equânime.

\section{CONSIDERAÇÕES FINAIS}

O objetivo desta pesquisa é verificar se as empresas do novo mercado BM\&F Bovespa referentes ao segmento de produtoras de petróleo, gás e biocombustíveis apresentam grau satisfatório de disclosure voluntário e obrigatório aos Stakeholders. Dessa forma, foi elaborado um Check List baseado no NBC T15 (Disclosure obrigatório) e na ISO 26000 (Disclosure voluntário) conforme demonstrado na metodologia desta pesquisa.

Os resultados mostram que os grupos 2, $3,4,5$, pertencentes ao disclosure obrigatório e o grupos 6 , relativo ao disclosure voluntário, foram evidenciados por apenas um quarto ou menos das empresas pesquisadas, e isto indica que o setor precisa evidenciar mais informações sobre estes aspectos. Por outro lado, informações dos grupos "Comportamento ético" (60\% de Disclosure) e "Respeito pelas normas internacionais de comportamento" (66\% de Disclosure), ambos pertencentes à divulgação voluntária, foram evidenciadas pela maioria das empresas pesquisadas.

A Petrobras apresentou o maior índice de divulgação, sugerindo que a empresa busca a excelência em diversos setores com os melhores resultados possíveis. Entretanto, as demais empresas apresentaram deficiências na divulgação de informações ao mercado e, dessa forma a média do setor ficou em 30\%.

Ressalta-se que, ao realizar uma análise das empresas no que diz respeito à divulgação de informações separando entre a evidenciação obrigatória e a voluntário, constatou-se que as informações voluntárias são mais divulgadas do que as informações obrigatórias. Assim, esta pesquisa propõe que, em estudos futuros, possam ser identificados e aprofundados as análises deste baixo índice de disclosure obrigatório, haja vista que se trata de uma divulgação compulsória, prevista em lei. 


\section{DISCLOSURE OF SOCIAL RESPONSIBILITY IN COMPANIES OF THE BIOFUEL SECTOR LISTED ON THE BM\&F BOVESPA}

\begin{abstract}
It has long been discussed the importance of disclosure of social responsibility of companies, making the effects of their economic activities more transparent to society. The interest in such information is not a Government exclusivity, but also the stakeholders (owners, managers, employees and potential investors). The objective of this work is to calculate and assess information related to voluntary and involuntary disclosure of social responsibility available on websites of companies producing oil, gas and biofuels linked to the new market of Bovespa BM\&F. This research has a qualitative approach with non-probabilistic sample, intentional and convenience. The results show that, in general, voluntary disclosure is more evident that the mandatory disclosure. The company Petrobras presented the highest levels of mandatory and voluntary disclosure. Regarding item analysis, it was observed that "ethical behavior" (60\% disclosure) and "Respect for international norms of behavior" $(66 \%$ disclosure), both belonging to the voluntary disclosure, had the highest levels of disclosure.
\end{abstract}

Keywords: Social Responsibility. Disclosure. Biofuel Sector.

\section{REFERÊNCIAS}

ASSOCIAÇÃO BRASILEIRA DE NORMAS TÉCNICAS. NBR ISO 26000: diretrizes sobre responsabilidade social. Rio de Janeiro: ABNT, 2010.

BM\&FBOVESPA. Website da Bolsa de Valores brasileira. Disponível em: $<$ http://www. bmfbovespa.com.br/pt_br/produtos/listados-a-vista-e-derivativos/renda-variavel/empresas-listadas.htm>. Acesso em: 13 jun. 2015.
BUENO, A. F. Problemas de disclosure no Brasil - o caso das empresas com ações no exterior. Caderno de Estudos Fipecafi, São Paulo, n. 20, jan./abr. 1999.

BUSHMAN, R.; SMITH, A. Financial accounting information and corporate governance. Journal of Accounting and Economics, Netherlands, v. 32, p. 237-333, 2001.

CARDOSO, V. I. Costa; DE LUCA, M. M. M.; GALLON, Al V. Reputação corporativa e o disclosure socioambiental de empresas brasileiras. Contabilidade, Gestão e Governança, Brasília, v. 17, n. 2, p. 26-44, 2014.

CARROLL, A. B. Corporate social responsibility: evolution of a definitional construct. Business and Society, United States, v. 38, n. 3, p. 268-295, 1999.

CARROLL, A. B.; SHABANA, K. M. Business case for corporate social responsibility: a review of concepts, research and practice. International Journal of Management Reviews, United Kingdom, v. 12, n. 1, p. 85-105, 2010 .

CHOI, F. D. S.; MUELLER, G. D. International accounting. 2th ed. New Jersey: Prentice Hall, 1992.

CLARO, P. B. O; CLARO, D. P; AMANCIO, R. Entendendo o conceito de sustentabilidade nas organizações. Revista de Admnistração, São Paulo, v. 43, n. 4, p. 289-300, out./nov./ dez. 2008. Disponível em: <www.rausp.usp. br/download.asp?file $=v 4304289 . p d f>$. Acesso em: 13 jun. 2015.

CONCEIÇÃO, S. H. et al. Fatores determinantes no disclosure em Responsabilidade Social Corporativa (RSC): um estudo qualitativo e quantitativo com empresas listadas na Bovespa. Revista Gestão e produção, São Paulo, v. 18, n. 3, p. 461-472, 2011. 
CONFEDERAÇÃO NACIONAL DA INDÚSTRIA (CNI). A contribuição do setor brasileiro de petróleo, gás e biocombustíveis para o desenvolvimento sustentável no país. Brasília: CNI, 2012.

CONSELHO FEDERAL DE CONTABILIDADE. Resolução CFC No 1.003/04 - NBC T15. de 19 de agosto de 2004. Aprova a NBC $T 15$ - informações de natureza social e ambiental. CFC, Brasília. Disponível em: $<$ http:// www.cfc.org.br/>. Acesso em: 12 ago. 2015.

CORDEIRO, C. M. R. Evidenciação (disclosure) das demonstrações financeiras: uma abordagem internacional. Revista Faculdade Santa Cruz, Curitiba, v. 3, n. 1, p. 1-7, 2003.

CVM - Comissão de Valores Mobiliários. Deliberação CVM n. 594/09. Disponível em: <http://www.cvm.gov.br>. Acesso em: 27 jun. 2015.

DANTAS, A. J. F. et al. Responsabilidade social sob a ótica da iso 26000: uma análise das pequenas empresas do comércio varejista de Mossoró. In: ENCONTRO INTERNACIONAL SOBRE GESTÃO EMPRESARIAL E MEIO AMBIENTE, 16., 2014, São Paulo. Anais... São Paulo: Engema,, 2014. p. 1-16.

DANTAS, J. A. et al. A dualidade entre os benefícios do disclosure e a relutância das organizações em aumentar o grau de evidenciação. In: ENCONTRO DA ASSOCIAÇÃO NACIONAL DE PÓS-GRADUAÇÃO E PESQUISA EM ADMINISTRAÇÃO, 28., 2004, Curitiba. Anais... Curitiba: Anpad, 2004. 1 CD-ROM.

FARIAS, M. R. S. Divulgação do passivo: um enfoque sobre o passivo contingente no setor químico e petroquímico brasileiro. 2004. $144 \mathrm{f}$. Dissertação (Mestrado em Ciências Contábeis) - Universidade de São Paulo, São Paulo, 2004.

FERNANDES, S. M. A influência do disclosure ambiental no custo de capital de terceiros das empresas brasileiras listadas na Bm\&FBovespa. In: SIMPÓSIO DE EXCELÊNCIA EM GESTÃO E TECNOLOGIA - SEGeT, 8., 2011, Rio de Janeiro. Anais... Rio de Janeiro: SEGeT, 2011. p. 1-14

FRIEDMAN, M. The social responsibility of business is to increase its profits. New York times, Sept., 126. 1962.

GARRIGA, E.; MELÉ, D. Corporate social responsibility theories: mapping the territory. Journal of Business Ethics, Netherlands, v. 53, n. 1/2, p. 51-71, 2004. Disponível em: $<\mathrm{http}$ :/www.jstor.org/stable/25123282>. Acesso em: 31 out. 2010.

GODOY, A. A. de J.; COSTA, S. R. C. Evidenciação, divulgação ou disclosure: aspectos teóricos e aplicações ao mercado financeiro. FCV Empresarial, Paraná, v. 1, p. 151-165, 2007.

HASSELDINE, J.; SALAMA, A. I.; TOMS, J. S. Quantity versus quality: the impact of environmental disclosures on the reputations of UK Plcs. British Accounting Review, United Kingdom, v. 37, n. 2, p. 231-248, jun. 2005.

IUDÍCIBUS, S. et al. Manual de contabilidade societária: aplicável a todas as Sociedades de acordo com as Normas Internacionais e do CPC. São Paulo: Atlas, 2010.

LEUZ, C.; VERRECCHIA, R. E. The Economic Consequences of Increased Disclosure (Digest Summary). Journal of accounting research, United States, v. 38, p. 91-124, 2000.

LIMA, G. A. S. F. de. Utilização da Teoria da Divulgação para avaliação da relação do nível de disclosure com o custo da dívida das empresas brasileiras. $2007.118 \mathrm{f}$. Tese (Doutorado em Controladoria e Contabilidade) Universidade de São Paulo, São Paulo. 2007.

LINDBLOM, C. The implications of organizational legitimacy for corporate social 
performance and disclosure. In: CRITICAL PERSPECTIVES ON ACCOUNTING CONFERENCE, New York, Vol. 120, 1994.

MURCIA, F. D. R.; SANTOS, A. dos. Teoria do disclosure discricionário: evidências do mercado brasileiro no período 2006-2008. In: CONGRESSO DA ASSOCIAÇÃO NACIONAL DOS PROGRAMAS DE PÓS-GRADUAÇÃO EM CIÊNCIAS CONTÁBEIS (ANPCONT), 4., 2010, Natal. 2010. Anais... Natal: Anpcont, 2010.

MUSSOI, A.; BELLEN, H.M.V. Evidenciação ambiental: uma comparação do nível de evidenciação entre os relatórios de empresas brasileiras. Revista de Contabilidade e Organizações, São Paulo, v. 4, n. 9, p. 55-78, 2010.

OLIVEIRA, A. F.; BENETTI, J. E.; VARELA, P. S. Disclosure das provisões e dos passivos e ativos contingentes: um estudo em empresas listadas na BM\&FBovespa. In: CONGRESSO DA ASSOCIAÇÃO NACIONAL DOS PROGRAMAS DE PÓS-GRADUAÇÃO EM CIÊNCIAS CONTÁBEIS (ANPCONT), 5., 2011, Vitória. Anais... Vitória: Anpcont, 2011. p. 1-15.

OLIVEIRA, J. A. P. Uma avaliação dos balanços sociais das 500 maiores. RAE Eletrônica, São Paulo, v. 4, n. 1, 2005. Disponível em: $<$ www.rae.com.br/eletronica $>$. Acesso em: 10 jan. 2007.

POTTER, M. E.; KRAMER, M.R. Strategy and society. the link between competitive advantage and corporate social responsibility. Harvard Business Review, United States, v. 84, n. 12, p. 78-92, Dec. 2006.

SOARES, G. M. P. Responsabilidade social corporativa: por uma boa causa!. RAE-eletrônica, v. 3, n. 2, jul./dez. 2004. Disponível em: <http:// rae.fgv.br/rae-eletronica/vol3-num2-2004/responsabilidade-social-corporativa-por-boa-causa>. Acesso em: 13 jun. 2015.
SOUZA, P. R. E. B. Análise do atual estágio de desclosure das companhias abertas no mercado de capitais brasileiro, contribuições para seu aprimoramento. 1995. Dissertação (Mestrado em Contabilidade) - Universidade de São Paulo, São Paulo, 1995.

STURDIVANT, F. D. Executives and activists: Test of stakeholder management. California Management Review, United States, v. 22, n. 1, p. 53-59, 1979.

TOMS, J. S. Firm resources, quality signals and the determinants of corporate environmentalreputation; some UK evidence. British Accounting Review, United Kingdom, v. 34, p. 257-282, 2002.

VERRECCHIA, R. E. Discretionary disclosure. Journal of accounting and economics, Netherlands, v. 5, p. 179-194, 1983. 